\title{
Argon plasma coagulation therapy for ablation of Barrett's oesophagus
}

\section{J Deviere}

Endoscopic thermoablation with argon plasma coagulation (APC) for Barrett's oesophagus is most effective for shorter segments but "buried" glands do occur. APC should remain in the area of experimental clinical studies

$\mathrm{B}$ arrett's oesophagus (BO) is undoubtedly associated with an increased risk of adenocarcinoma of the oesophagus. ${ }^{1}$ Now that therapeutic endoscopy techniques have improved, it is therefore tempting to ablate Barrett's intestinal metaplasia in order to decrease the risk of tumour development. However, ablation therapy is still controversial, especially for patients having no dysplasia, due to: (1) their low risk of cancer; (2) the risk associated with the technique of ablation; and (3) the fact that we do not know if Barrett's ablation will really decrease the risk of cancer in the long term in an individual patient.

The rationale for current ablative therapy began with the observation that destruction or ablation of intestinal metaplasia associated with acid suppression results in its rapid replacement by a squamous epithelium. ${ }^{2}$ Several groups of investigators have performed clinical studies evaluating the effectiveness of BO ablation associated with proton pump inhibitor (PPI) treatment. For patient having non-dysplastic BO without dysplasia, argon plasma coagulation (APC) has been the most popular technique. ${ }^{3-8}$ After $1-6$ sessions, a success rate of $\mathrm{BO}$ eradication ranging from $42 \%$ to $98 \%$ was achieved. Chest pain was very frequent after treatment and other complications were unusual, although not negligible since they included strictures, ${ }^{378}$ fever, ${ }^{8}$ bleeding, ${ }^{3}$ or even perforation and death. ${ }^{48}$ More importantly for the long term usefulness of this therapy was the observation of persisting buried intestinal metaplasia under the squamous re-epithelialisation, which was observed in the first clinical trials $s^{3-5}$ with a frequency of $8-30 \%$. Also, at least two cases of adenocarcinoma arising under the squamous reepithelialisation have been observed after APC, ${ }^{910}$ suggesting that even surveillance (and biopsy targeting) could become more difficult after this therapy. More recent trials ${ }^{78}$ have observed a very low incidence of buried glands, probably because of the use of higher PPI doses and of higher power settings of the APC resulting in a deeper injury, but also at the cost of a higher incidence of strictures. In the current issue of Gut, Basu and colleagues ${ }^{11}$ report on a series of 50 patients with BO treated by APC and followed for one year [ see page 776]. They used a 30 watt power setting of APC (which corresponds to the low rage of energy) and cleared the BO macroscopically in $68 \%$ of cases, but $44 \%$ of those successful cases had buried glands at histology. As reported in other studies, ${ }^{3}$ they found that the length of $\mathrm{BO}$ was a predictive factor for persistence after treatment. There was a slight trend for persistent acid reflux in cases where eradication was not achieved but this was difficult to evaluate as PPI doses were adjusted to reach effective acid suppression. At one year, they observed a higher rate of BO recurrence in patients who had reduced their PPI use, suggesting that, if eradication is obtained, it should be followed by lifelong high dose PPI therapy to avoid recurrence.

An interesting finding of this paper was the trend towards more severe biliary reflux among patients with persistent BO at the end of treatment, suggesting that acid reflux is not the only factor to be considered when examining the mechanisms affecting outcome of such therapy. Unfortunately, the authors did not perform bilimetry in all patients and may have compromised their chance of reaching a significant difference in this evaluation of biliary reflux and characterising the "factors determining persistence and recurrence of $\mathrm{BO}^{\prime \prime}$

Another major concern of such ablative therapy is cost effectiveness. Even if it was successful in every patient, the cost of a median of three endoscopic therapy sessions is not negligible. To that the cost of potential complication management has to be added, and may be significant, especially when higher power APC is used. Moreover, as suggested in this paper, if high doses of PPI have to be taken for life, this will further enhance the total cost. This might be justified if no further follow up is needed. However, taking into account that in this study after one year less than $50 \%$ of patients were clear of $\mathrm{BO}$ and that there was no evidence that surveillance could be avoided in some of the treated patients, endoscopic ablation therapy for non-dysplastic Barrett's increased the cost of patient management without evidence of benefit.

Other ablative therapies (PDT, mucosectomy) have been shown recently to be useful in patients with $\mathrm{BO}$ and severe dysplasia or early carcinoma ${ }^{12-15}$ and are currently the most interesting area of therapeutic endoscopy application in BO, especially in patients at higher risk of surgery (who are numerous among BO cases). These techniques are however associated with a higher rate of complications and not applicable for nondysplastic BO. The study of Basu et al stresses that ablation of non-dysplastic $\mathrm{BO}$ is far from being proved useful for patients and should strictly remain in the area of experimental clinical studies.

Gut 2002;51:763-764

\section{Author's affiliation}

J Deviere, Department of Gastroenterology, "ULB, Hospital Erasme", Bruxelles B 1070,

Belgium; ideviere@ulb.ac.be

\section{REFERENCES}

1 Spechler SJ, Lee E, Ahnen D, et al. Long-term outcome of medical and surgical therapies for gastroesophageal reflux disease: follow-up of a randomized controlled trial. JAMA 2001;285:2331-8.

2 Berenson MM, Johnson TD, Markowitz NR, et al. Restoration of squamous mucosa after ablation of Barrett's esophageal epithelium Gastroenterology 1993;104:1686-91.

3 Van Laethem JL, Cremer M, Peny MO, et al. Eradication of Barrett's mucosa with argon plasma coagulation and acid suppression: immediate and mid term results. Gut 1998;43:747-51.

4 Byrne JP, Armstrong GR, Attwood SE. Restoration of the normal squamous lining in Barrett's esophagus by argon beam plasma coagulation. Am J Gastroenterol 1998;93:1810-15.

5 Mork $\mathbf{H}$, Barth T, Kreipe $\mathrm{HH}$, et al. Reconstitution of squamous epithelium in Barrett's oesophagus with endoscopic argon plasma coagulation: a prospective study. Scand J Gastroenterol 1998;33:1130-4

6 Grade AJ, Shah IA, Medlin SM, et al. The efficacy and safety of argon plasma coagulation therapy in Barrett's esophagus. Gastrointest Endosc 1999;50: 18-22.

7 Schulz H, Miehlke S, Antos D, et al. Ablation of Barrett's epithelium by endoscopic argon plasma coagulation in combination with high-dose omeprazole. Gastrointest Endosc 2000;51:659-63.

8 Pereira-Lima JC, Busnello JV, Saul C, et al. High power setting argon plasma coagulation for the eradication of Barrett's esophagus. Am J Gastroenterol 2000;95:1661-8.

9 Van Laethem JL, Peny MO, Salmon I, et al. Intramucosal adenocarcinoma arising under squamous re-epithelialisation of Barrett's oesophagus. Gut 2000:46:574-7.

10 Shand A, Dallal H, Palmer K, et al. Shand A, Dallal H, Palmer K, et al.
Adenocarcinoma arising in columnar lined oesophagus following treatment with argon plasma coagulation. Gut 2001:48:580-1.

11 Basu KK, Pick B, Bale R, et al. Efficacy and one year follow up of argon plasma 
coagulation therapy for ablation of Barrett's oesophagus: factors determining persistence and recurrence of Barrett's epithelium. Gut 2002;51:776-80.

12 Ell C, May A, Gossner L, et al. Endoscopic mucosal resection of early cancer and high-grade dysplasia in Barrett's esophagus. Gastroenterology 2000; 1 18:670-7.
13 Gossner L, May A, Sroka R, et al. Photodynamic destruction of high grade dysplasia and early carcinoma of the esophagus after the oral administration of 5-aminolevulinic acid. Cancer 1999:86:1921-8

14 Overholt BF, Panjehpour M, Haydek JM. Photodynamic therapy for Barrett's esophagus: follow-up in 100 patients. Gastrointest Endosc 1999:49:1-7.

15 Niihawan PK, Wang KK. Endoscopic mucosal resection for lesions with endoscopic features suggestive of malignancy and high-grade dysplasia within Barrett's esophagus. Gastrointest Endosc 2000;52:328-32.

\section{Appendix redux}

\section{B Sachar}

\section{Appendicectomy has a protective effect in Crohn's disease and ulcerative colitis, and the course of ulcerative colitis seems milder following a history of appendicectomy}

T he endless "genetics or environment" debate can get rather convoluted, whether about inflammatory bowel disease (IBD) or any other complex disease. ${ }^{1}$ With regard to IBD, a series of epidemiological and genetic "breakthroughs" have barely inched us closer to clarifying this issue. ${ }^{2}$ Indeed, many decades of research on Crohn's disease and ulcerative colitis have so far revealed just one principal gene, at the NOD2 locus on chromosome $16,{ }^{3}$ and one major environmental factor, smoking, ${ }^{4}$ in influencing susceptibility to either of these conditions.

Currently, the "Crohn's disease gene" is the hottest topic but environmental issues keep pushing themselves into the picture. The "protective" effects of smoking in ulcerative colitis have been old news for a while, with its deleterious effects in Crohn's disease only more recently coming to the fore. ${ }^{6}$ But all of the observations on smoking over the past 20 years have not really helped us very much, despite intriguing hypotheses about pathogenesis $^{7}$ and treatment. ${ }^{8}$

Now a newer factor, the role of the appendix, is attracting increasing interest. ${ }^{9}$ Actually, this factor is not particularly "new" at all, since Gilat et al called attention to it as a possible "childhood factor" in $1987,{ }^{10}$ while innumerable clinical and pathological observations about the appendix in IBD were being published throughout at least the 20 years before. ${ }^{11}$ None the less, it was not until the mid-1990s that intensive investigations began focusing quite sharply on the associations between prior appendicectomy and the incidence of IBD—or, more specifically, ulcerative colitis.

Both of the studies on this subject in the current issue of Gut $^{12}{ }^{13}$ fall thoroughly into step with all previous studies suggesting a "protective" effect of prior appendicectomy against the incidence of ulcerative colitis [see pages 803 and 808]. Each of these two papers in its own way however sheds new light on the topic. Both are meticulous in the application of multivariate analyses to dissect out confounding effects such as age, sex, and smoking, although the French study includesd many more factors in its proportional hazards regression model. Both are equally careful to correct for the bias of appendicectomy at the time of diagnosis.

The Australian study is broader in scope in that it includes Crohn's disease patients and population controls while the French investigators concentrate exclusively on ulcerative colitis patients; but both series are very large (over 600 cases) and both comprise ambulatory as well as hospitalised cases. Another welcome feature of both papers is that they use clear and appropriate definitions of disease characteristics and severity, including endoscopic data, therapeutic requirements, and rates of surgery. Only the French study calculates the proportion of years in which disease was active as a measure of severity, and only the Australian study incorporates histology in defining disease extent, as well as specifically excluding surgery for neoplasia as a severity measure; but overall both papers employ very reasonable criteria.

So with all these excellent qualities to their credit, just where is the "new light" that these two papers purportedly shed? I would cite two areas of particular illumination. Firstly, from the Australian group we learn for the first time that a large and well controlled study shows a "protective" effect of appendicectomy in Crohn's disease as well as in ulcerative colitis. This observation leaves smoking as still virtually the only epidemiological factor that works in opposite directions in these two diseases. Secondly, from both of these papers, a combined sample size of 62 ulcerative colitis patients with prior appendicectomy provides confirmation of an earlier suggestion, based on only 21 such cases, that the course of ulcerative colitis seems milder following a history of appendicectomy. ${ }^{14}$

But what issues remain in the dark despite these two important new papers? Very simply, what remains obscure is the meaning of it all. The French and Australian authors are quite candid in admitting that their data can be interpreted in two different ways. Either the appendix itself exerts a truly "protective" effect against IBD by virtue of immunological mechanisms that both papers discuss thoroughly; or else young people who develop appendicitis or mesenteric adenitis are somehow physiologically, genetically, or immunologically distinct from the population that is predisposed to IBD. A recent article from Sweden seems to suggest that it is the appendicitis more than the appendicectomy per se that is protective. ${ }^{15}$ Radford-Smith et al however tilt slightly in favour of the "appendicectomy" hypothesis while fully acknowledging the validity of the "appendicitis" theory. Cosnes et al lean even further in the same direction, going almost overboard in their recommendation for prophylactic appendicectomy among "patients (sic) genetically at high risk of developing ulcerative colitis."

In either event, the statistical observations reported in this issue of Gut are certainly consistent with each other as well as with previous studies, and they undoubtedly offer tantalising clues to the pathogenesis of IBD. But Tantalus never did get to eat or drink the food and water surrounding him, and it seems we too are going to have to wait a lot longer before satisfying our own hunger and thirst for understanding everything about IBD.

\section{Gut 2002;51:764-765}

\section{Author's affiliation}

D B Sachar, Mount Sinai School of Medicine, New York, USA; david.sachar@mssm.edu

\section{REFERENCES}

1 Sachar DB. Genomics and phenomics in Crohn's disease. Gastroenterology 2002; 122:161-2.

2 Van Kruiningen HJ, Cortot A, Colombel J-F. The importance of familial clusterings in Crohn's disease. Inflamm Bowel Dis 2001; 7:170-3. 
3 Cho JH. The Nod2 gene in Crohn's disease: implications for future research into the genetics and immunology of Crohn's disease. Inflamm Bowel Dis 2001;7:271-5.

4 Rubin DT, Hanauer SB. Smoking and inflammatory bowel disease. Eur J Gastroenterol Hepatol 2000;12:855-62.

5 de Castella H. Non-smoking: a feature of ulcerative colitis. BM 1982;284:1706.

6 Lindberg E, Jarnerot G, Huiffeldt B. Smoking in Crohn's disease: effect on localisation and clinical course. Gut 1992;33:779-82.

7 Pullan RD. Colonic mucus, smoking and ulcerative colitis. Ann R Coll Surg Engl 1996:78:85-91.
8 Thomas GA, Rhodes J, Green JT, et al. Role of smoking in inflammatory bowel disease: implications for therapy. Postgrad Med J 2000;76:273-9.

9 Koutroubakis IE, Vlachonikolis IG Kouroumalis EA. Role of appendicitis and appendectomy in the pathogenesis of ulcerative colitis: a critical review. Inflamm Bowel Dis 2002:8:277-86

10 Gilat $T$, Hacohen $D$, Lilos $P$, et al. Childhood factors in ulcerative colitis and Crohn's disease: an international cooperative study. Scand J Gastroenterol 1987;22:1009-24.

11 Koslowski E, De Cort J. Crohn's disease of the appendix (Dutch). Tiidschr Gastroenterol 1966;9:491-3
12 Cosnes J, Carbonnel F, Beaugerie L, et al Effects of appendicectomy on the course of Effects of appendicectomy on the cours
ulcerative colitis. Gut 2002;51:803-7.

13 Radford-Smith GL, Edwards JE, Purdie DM, et al. Protective role of appendicectomy on onset and severity of ulcerative colitis and Crohn's disease Gut 2002:51:808-13.

14 Naganuma $M$, lizuka $B$, Torii $A$ et al. Appendectomy protects against the development of ulcerative colitis and reduces its recurrence: results of a multicenter case-controlled study in Japan. Am J Gastroenterol 2001;96:1123-6.

15 Andersson RE, Olaison G, Tysk C, et al. Appendectomy and protection against uppendectomy and protection ulcerative colitis. N

\section{Risk of pancreatic ductal adenocarcinoma in chronic pancreatitis}

\section{N Howes, J P Neoptolemos}

\section{Patients with chronic pancreatitis have a markedly increased risk of pancreatic cancer compared with the general population}

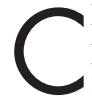
ronic pancreatitis has been proposed as an independent risk factor for the development of pancreatic cancer in a number of important studies. ${ }^{1-3}$ Problems with methodology however, such as patient selection, ascertainment bias, small patient numbers, and stringency of patient selection have been major criticisms, leading some authors to believe that the risk of pancreatic cancer in chronic pancreatitis is confounded by other risk factors such as smoking. ${ }^{4}$ The study presented by Malka and colleagues ${ }^{5}$ in this issue of Gut has addressed some of these considerations, in that it has prospectively followed a cohort of 373 patients with proven chronic pancreatitis, defined by stringent criteria, over a median of 9.2 years [ $\mathbf{s e e}$ page 849]. The high incidence of pancreatic calcification $(83 \%)$, elective surgery (60\%), diabetes mellitus (54\%), pseudocysts (46\%), and venous occlusive disease $(21 \%)$ leave little room for doubt that this is a true cohort of patients with chronic pancreatitis. Patients with pancreatic cancer were confirmed histologically in all cases and careful consideration was given to patients that were lost to follow up. The results of the study suggest a significantly overall increased risk of pancreatic cancer (standardised incidence ratio 26.7) in chronic pancreatitis.

The majority of patients in this study had alcoholic pancreatitis (85\%); patients with chronic pancreatitis however are a heterogeneous group, with chronic pancreatitis of other aetiologies having a much greater risk for the development of pancreatic cancer. Hereditary pancreatitis, an autosomal dominant disease presenting in childhood that is histologically identical to chronic pancreatitis of other aetiologies, has a 53-fold increased risk for the development of pancreatic cancer. ${ }^{6}$ The risk of developing pancreatic cancer in chronic pancreatitis is also related to the age of the patient. Whether this is a reflection of the age per se or the duration of chronic pancreatitis is unclear. Lowenfels et al, in a study of 1552 patients with chronic pancreatitis, found a marked independent increase in pancreatic cancer with age such that the relative risk for the development of pancreatic cancer was more than three times greater for a patient over the age of 60 years compared with younger patients. In a similar study in patients with hereditary pancreatitis, the risk of pancreatic cancer was negligible below the age of 40 years but increased greatly with age such that the overall lifetime risk to aged 70 was $40 \%$.

Cigarette consumption is an important consideration in any study evaluating cancer risk, particularly in chronic pancreatitis where a high proportion of patients smoke. A number of studies have identified smoking as an independent variable in the development of pancreatic cancer, and demonstrated that there is a relationship to the number of cigarettes consumed..$^{78}$ In a multivariate analysis of 497 patients with hereditary pancreatitis, smoking was found to independently double the risk of pancreatic cancer and accounted for approximately $25-30 \%$ of all pancreatic tumours. Pancreatic cancer also developed some 20 years earlier in smokers compared with non-smokers, suggesting that smoking compounds the risk of pancreatic cancer in chronic pancreatitis. $^{.}$

Leaving epidemiological studies aside, there is some biological evidence supporting the development of chronic pancreatitis to pancreatic ductal adenocarcinoma. Ductal dysplasia, which is relatively common in chronic pancreatitis, has been demonstrated in the pancreas of patients with pancreatic cancer. More importantly, there is a stepwise progression from mild to severe dysplasia within the pancreatic ducts ${ }^{10}$ suggesting a temporal relationship of these ductal lesions and pancreatic cancer. Molecular analysis of pancreatic ductal lesions, similar to those found in chronic pancreatitis, has demonstrated identical molecular lesions as those found in infiltrating ductal adenocarcinomas of the pancreas. K-ras mutations have been described in ductal lesions with minimal atypia and as such are "early" genetic events in carcinogenesis. ${ }^{11-13}$ Mutations in the pl6 gene occur at a later stage in carcinogenesis. Yamano et al showed loss of heterogeneity of the pl6 loci in 13\% of histologically low grade pancreatic ductal lesions compared with $90 \%$ of high grade lesions. ${ }^{14}$ Loss of expression of $\mathrm{pl6}$, another tumour suppressor gene thought to be important in the development of pancreatic cancer, was found in 60/126 microdissected intraductal lesions. More significantly, loss of expression of pl6 was seen in atypical lesions three times more often than nonatypical lesions, suggesting that loss of pl6 expression occurs more frequently in higher grade duct lesions. ${ }^{15}$ Loss of expression of pl6 and another tumour suppressor gene SMAD4 have also been seen in pancreatic ductal lesions, but unlike K-ras and pl6, these mutations 
are seen in lesions with significant atypia or carcinoma in situ. ${ }^{16}{ }^{17} \mathrm{~A}$ more direct link may lie in the chronic activation of trypsinogen and activation by trypsin of the matrix metalloproteinase matrilysin (MMP-7), ${ }^{18}$ increased activity of which is now recognised as one of the earliest events in the molecular pathogenesis of pancreatic cancer. ${ }^{19}$

Further confirmation of chronic pancreatitis as a risk factor for pancreatic cancer is important from a clinical prospective, particularly with respect to screening. It is clear that unstructured screening of all patients with chronic pancreatitis is unlikely to be of benefit as existing tests are not sufficiently sensitive or specific to result in patients with cancer being detected with the required positive and negative predictive values to enable screening to be effective. It is apparent however that there are subsets of patients with chronic pancreatitis where their individual risk of pancreatic cancer may be sufficiently high to justify screening. Given also that there appears to be a progression of molecular mutations in patients with developing pancreatic cancer, screening using a combination of imaging and molecular tests may be justified in older ( $>40-50$ years) patients with the non-inherited as well as the inherited forms of chronic pancreatitis. ${ }^{20}$

\section{ACKNOWLEDGEMENTS}

The authors wish to acknowledge the support of the European Registry of Hereditary Pancreatitis and Pancreatic Cancer (EUROPAC; europac@liv.ac.uk; http:// www.liv.ac.uk/surgery/europac.html) and grants from the Medical Research Council, Cancer Research UK, North West Cancer Research Fund, North West NHS R\&D, Royal
Liverpool University Hospital R\&D, Solvay Health Care GmbH, Hanover, and the Augustus Newnham Foundation.

\section{Gut 2002;51:765-766}

\section{Authors' affiliations}

N Howes, J P Neoptolemos, Department of Surgery, University of Liverpool, Liverpool, UK

Correspondence to: Professor J P Neoptolemos, Department of Surgery, 5th Floor UCD Building, Daulby Street, Liverpool L69 3GA, UK; i.p.neoptolemos@liverpool.ac.uk

\section{REFERENCES}

1 Ekbom A, Mclaughlin JK, Karlsson BM, et al. Pancreatitis and pancreatic cancer: a population-based study. J Natl Cancer Inst 1994:86:625-7.

2 Lowenfels AB, Maisonneuve P, Cavallini G, et al. Pancreatitis and the risk of pancreatic cancer. International Pancreatitis Study Group. N Engl J Med 1993;328:1433-7.

3 Talamini G, Bassi $C$, Falconi $M$, et al Alcohol and smoking as risk factors in chronic pancreatitis and pancreatic cancer. Dig Dis Sci 1999:44:1303-11.

4 Karlson BM, Ekbom A, Josefsson S, et al. The risk of pancreatic cancer following pancreatitis: an association due to confounding? Gastroenterology 1997;113:587-92.

5 Malka D, Hammel P, Maire F, et al. Risk of pancreatic adenocarcinoma in chronic pancreatitis. Gut 2002;51:849-852.

6 Lowenfels AB, Maisonneuve P, DiMagno EP, et al. Hereditary pancreatitis and the risk of pancreatic cancer. International Hereditary pancreatic cancer. International Hereditary 1997;89:442-6.

7 Coughlin SS, Calle EE, Patel AV, et al. Predictors of pancreatic cancer mortality among a large cohort of United States adults. Cancer Causes Control 2000;11:915-23.

8 Harnack LJ, Anderson KE, Zheng W, et al. Smoking, alcohol, coffee, and tea intake and incidence of cancer of the exocrine pancreas: the lowa Women's Health Study. Cancer Epidemiol Biomarkers Prev 1997;6: 1081-6.

9 Lowenfels AB, Maisonneuve P, Whitcomb DC, et al. Cigarette smoking as a risk factor for pancreatic cancer in patients with hereditary pancreatitis. JAMA

2001;286:169-70.

10 Furukawa T, Chiba R, Kobari $M$, et al. Varying grades of epithelial atypia in the pancreatic ducts of humans. Classification based on morphometry and multivariate analysis and correlated with positive reactions of carcinoembryonic antigen. Arch Pathol Lab Med 1994; 118:227-34

11 Luttges J, Schlehe B, Menke MA, et al. The K-ras mutation pattern in pancreatic ductal adenocarcinoma usually is identical to that in associated normal, hyperplastic, and metaplastic ductal epithelium. Cancer 1999;85:1703-10.

12 Sugio K, Molberg K, Albores-Saavedra J, et al. K-ras mutations and allelic loss at $5 q$ and $18 \mathrm{q}$ in the development of human pancreatic cancers. Int J Pancreatol 1997;21:205-17.

13 Matsubayashi H, Watanabe $\mathrm{H}$, Nishikura K, et al. Determination of pancreatic ductal carcinoma histogenesis by analysis of mucous quality and K-ras mutation. Cancer 1998:82:651-60.

14 Yamano $M$, Fujii $H$, Takagaki $T$, et al. Genetic progression and divergence in pancreatic carcinoma. Am J Patho 2000;156:2123-33.

15 Wilentz RE, Geradts J, Maynard R, et al Inactivation of the pl6 (INK4A) tumor-suppressor gene in pancreatic duct lesions: loss of intranuclear expression. Cancer Res 1998;58:4740-4

16 Wilentz RE, lacobuzio-Donahue CA, Argani $P$, et al. Loss of expression of Dpc4 in pancreatic intraepithelial neoplasia: evidence that DPC4 inactivation occurs late in neoplastic progression. Cancer Res 2000;60:2002-6.

17 Hruban RH, Wilentz RE, Kern SE. Genetic progression in the pancreatic ducts. Am J Pathol 2000; 156: 1821-5.

18 Imai K, Yokohama Y, Nakanishi I, et al. Matrix metalloproteinase 7 (matrilysin) from human rectal carcinoma cells. Activation of the precursor, interaction with other matrix metalloproteinases and enzymic properties. $J$ Biol Chem 1995;270:6691-7.

19 Crawford HC, Scoggins CR, Washington MK, et al. Matrix metalloproteinase-7 is expressed by pancreatic cancer precursors and regulates acinar-to-ductal metaplasia in exocrine pancreas. J Clin Invest 2002; 109: 1437-44

20 Wong T, Howes N, Threadgold J, et al. Molecular diagnosis of early pancreatic ductal adenocarcinoma in high risk patients. Pancreatology 2001;1:486-509. 